\title{
Association of Gastric Cancer and Gastrointestinal Stromal Tumor: A Case Report
}

Younes Hamdouni", Houssam Belghali, Tarik Souiki, Karim Ibn Majdoub Hassani, Imane Toughrai, Khalid Mazaz

Visceral Surgery Service, Hassan II University Hospital, Faculty of Medicine and Pharmacy of Fez, Sidi Mohammed Ben Abdallah University, Fez, Morocco

DOI: $\underline{10.36347 / \text { sasjs.2021.v07i02.002 }}$

| Received: 17.01.2021 | Accepted: 01.02.2021 | Published: 05.02.2021

*Corresponding author: Younes Hamdouni

\section{Abstract}

Gastrointestinal stromal tumors are the most frequent mesenchymal tumors, yet their association with adenocarcinoma is rare, only a few clinical cases are reported in the literature. We report the case of a 65 -year-old woman, followed at the University Hospital of Fez, for a pyloric adenocarcinoma, in whom the extension assessment revealed a stromal tumor of the gastrointestinal type at the expense of a jejunal loop. We describe through this observation the epidemiological and clinical aspects, and the particularities of the management of this rare association.

Keywords: Pyloric cancer, Jejunal GIST, association.

Copyright $(\mathcal{C} 2021$ The Author(s): This is an open-access article distributed under the terms of the Creative Commons Attribution 4.0 International License (CC BY-NC 4.0) which permits unrestricted use, distribution, and reproduction in any medium for non-commercial use provided the original author and source are credited.

\section{INTRODUCTION}

The synchronous development of an epithelial and stromal tumor in the digestive tract has been rarely reported in the literature, and poses many diagnostic and therapeutic difficulties. Analysis of the data in the literature reports a few isolated cases.

\section{PATIENT AND OBSERVATION}

This is Mrs. R. A, without notable pathological history, who has presented for 18 months low abundance hematemesis without transit disorders, all evolving in a context of weight loss estimated at $12 \mathrm{~kg}$ and apyrexia. The abdominal examination revealed a flexible abdomen with no palpable mass. The rectal examination: traces of blood.

Gynecological and mucocutaneous examination: conjunctival discoloration. The ganglionic areas are free. The rest of the review is unremarkable.

Esogastroduodenal endoscopy showed the presence of a stenosing and friable passable pyloric ulcer- budding process. The biopsies concluded in a moderately differentiated and infiltrating adenocarcinoma.

A thoracoabdominal CT scan showed tumor thickening off the pyloro-duodenal junction, producing a true massively necrotic nodular mass measuring 30 $\mathrm{mm}$ in thickness and $29 \mathrm{~mm}$ in height, initially suggesting GIST.

Presence of a tumor mass at the expense of an eccentric jejunal loop with exophytic development (subserosa) measuring 44 × $29 \mathrm{~mm}$, well circumscribed, hyper vascularized with discreet central necrotic changes.

The liver is of normal size, of regular contours, seat of a simple cystic lesion at the level of segment II measuring $14 \mathrm{~mm}$.

Absence of suspect digestive wall thickening.

Absence of deep ADP.

Lack of intraperitoneal effusion.

Absence of suspicious bone lesion.

Moreover, on the thoracic level, no secondary lesion has been objectified.

The care offered during the multidisciplinary consultation meeting

Was chemotherapy first then surgery.

The patient underwent a partial gastrectomy associated with resection of the fine stromal tumor with end-to-end fine-to-fine anastomosis.

The post-operative consequences were simple. The patient received adjuvant chemotherapy. 
Younes Hamdouni et al., SAS J Surg, Feb, 2021; 7(2): 38-40

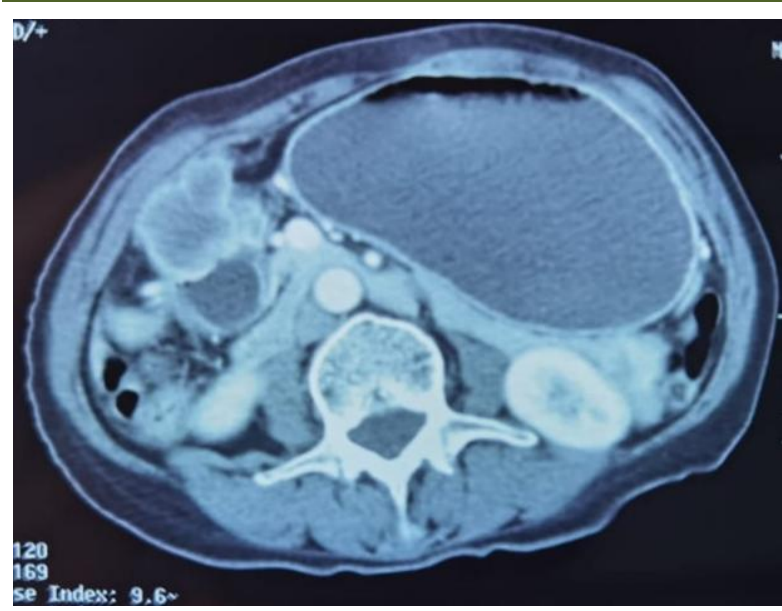

Fig-1: A CT image showing an eccentric tumor thickening of the pyloro-duodenal junction, with the presence of a tumor mass at the expense of an eccentric jejunal loop with exophytic development

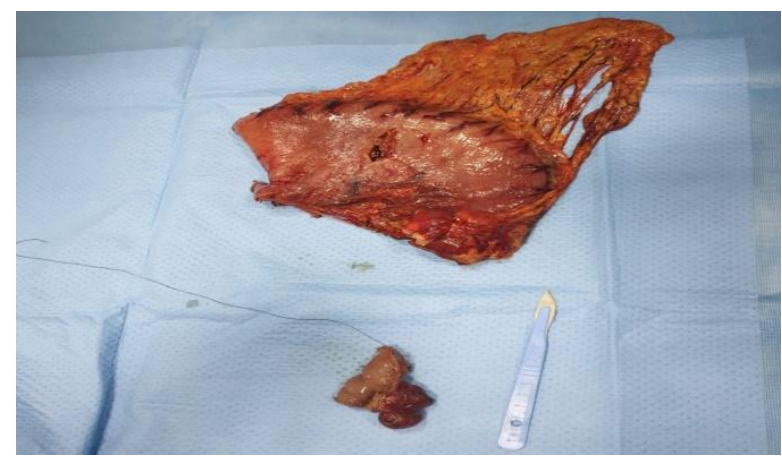

Fig-2: The surgical specimen of gastric tumor with small stromal tumor

\section{DISCUSSION}

The association of gastrointestinal stromal tumors (GIST) with other primary tumors is rare, it is seen mainly with tumors of the digestive tract (47\% of cases of associations) [1].

The majority of gastrointestinal stromal tumors are discovered intraoperatively during surgery for another digestive tumor, or accidentally following a radiological or endoscopic assessment [2].

The relationship between gastric epithelial and stromal tumors is not yet clear. The question of whether such an occurrence is a mere fortuitous association or whether the two lesions are linked by a causal relationship remains unresolved. However, previous studies have shown that unknown potential carcinogens can stimulate simultaneous proliferation and oncogenesis in epithelial and stromal cells [3-9].

In the current state of knowledge, the hypothesis that may explain the coexistence of GIST and gastric cancer can be genetically justified by the occasional overexpression of the c-kit gene on the surface of malignant stromal cells of the digestive tract. Large-scale studies are needed to be able to confirm this in order to deduce targeted therapies that may prove to be effective in the treatment [10-12].

\section{CONCLUSION}

The coexistence of GIST with synchronous or metachronous gastric cancer represents a phenomenon with an increasing number of related reports in the literature over the past 5 years.

In all cases of GIST (with or without preoperative histopathological confirmation), the surgeon must be vigilant to recognize a possible coexisting tumor of different histological origin and to perform a thorough preoperative and intraoperative control. The correct diagnosis before and at the time of surgery is the cornerstone that guarantees the best prognosis for patients.

Informed Consent: The author stated that the written consent was received from the patient who was presented in this study.

\section{REFERENCE}

1. Takeuchi H, Hiroshige $\mathrm{S}$, Hashimoto $\mathrm{K}$, Kusumoto T, Yoshikawa Y, Muto Y. Synchronous double tumor of breast cancer and gastrointestinal stromal tumor in a patient with neurofibromatosis type 1: report of a case. Anticancer research. 2011 Dec 1;31(12):4481-4.

2. Lin YL, Tzeng JE, Wei CK, Lin CW. Petite tumeur stromale gastro-intestinale concomitante avec un cancer gastrique précoce: un rapport de cas. Journal mondial de gastroentérologie: WJG. 2006; 12: 815-817.

3. Crew KD, Neugut AI. Épidémiologie du cancer gastrique. Monde J gastroentérol. 2006; 12:354362 .

4. Nishino N. Lymphome synchrone et adénocarcinome survenant sous forme de tumeur de collision dans l'estomac: rapport de cas. Chirurgie aujourd'hui. 1996; 26: 508-512.

5. Cypriano MS, Jenkins JJ, Pappo AS, Rao BN, Daw NC. Tumeurs stromales gastro-intestinales pédiatriques léiomyosarcome. Cancer. 2004; 101: 39-50.

6. Kallakury BV. Adénosarcome gastrique primaire. Archives de pathologie et médecine de laboratoire. 1993; 117: 299-301.

7. Pai SA, Kher N, Krishnamurthy S. Tumeur de collision avec trois composants à la jonction œsophagogastrique. Journal indien de gastroentérologie: journal officiel de la société indienne de gastroentérologie. 1997; 16: 116-116.

8. Bircan S. Adénocarcinome primaire synchrone et tumeur stromale gastro-intestinale dans l'estomac: un rapport de deux cas. Turk J gastroentérol. 2004; 15:187-191.

9. Liu SW, Chen GH, Hsieh PP. Tumeur de collision de l'estomac: un rapport de cas de tumeur stromale gastro-intestinale et 
d'adénocarcinome. Journal de gastroentérologie clinique. 2002; 35: 332-334.

10. Andea AA, Lucas C, Cheng JD, Adsay NV. Apparition synchrone de tumeurs épithéliales et stromales dans l'estomac. Archives de pathologie et médecine de laboratoire. 2001; 125 : 318-318.

11. Rauf F, Ahmad Z, Muzzafar S, Hussaini AS. Occurrence synchrone de la tumeur stromale gastro-intestinale et de l'adénocarcinome gastrique: un rapport de cas. Association médicale Journal-Pakistan. 2006; 56 : 184-186.

12. Liszka Ł, Zielińska-Pająk E, Pająk J, Gołka D, Huszno J. Coexistence de tumeurs stromales gastro-intestinales avec d'autres néoplasmes. Journal de gastroentérologie. 2007; 42: 641-649. 